\title{
Case Studies of Local CPA Firms' Audit Quality
}

\author{
Jiexiao Shan \\ Management School, Jinan University, Guangzhou, China \\ Email: jaxijaxi@126.com
}

Received 26 October 2015; accepted 13 November 2015; published 16 November 2015

Copyright (C) 2015 by author and Scientific Research Publishing Inc.

This work is licensed under the Creative Commons Attribution International License (CC BY). http://creativecommons.org/licenses/by/4.0/

c) (i) Open Access

\begin{abstract}
Using two state-owned enterprises' financial fraud cases, Nanjing Zhongbei Group Co., Ltd. and Nanjing Textiles Import \& Export Corp., Ltd., which were audited by the same local CPA firm, we found that the auditors of the two companies were almost the same and the fraud time of the two companies was close. We further analyze the reasons why the CPA firm still issues standard opinions for such fraud and "sick" auditors violate again. Finally, we propose some policy suggestions.
\end{abstract}

\section{Keywords}

Financial Fraud, Local CPA Firm, Audit Quality

\section{Introduction}

In 2010, the China Securities Regulatory Commission punished Nanjing Zhongbei Group Co., Ltd., a local state-owned enterprise, for its illegal information disclosure. The company's annual reports hid huge borrowing up to 1.3 billion yuan and the related-party guarantee of more than 40 million yuan in 2003 and 2004. In 2014, the China Securities Regulatory Commission punished Nanjing Textiles Import \& Export Corp., Ltd., another local state-owned enterprise, for its inflated profits. The company made up profit more than 300 million yuan from 2006 to 2010, which was the most serious SOEs’ financial fraud in recent 10 years.

The financial reports of listed companies must be audited by the CPA firm. The CPA firm of the two listed companies was the same local CPA firm, Nanjing Lixin Yonghua CPA firm. The auditors all issued standard opinions during the fraud period of the two companies. Confusingly, the two companies' fraud time was relatively long and the amount of money was huge, especially Nanjing Textiles Import \& Export Corp., Ltd., whose inflated profits were more than 300 million yuan from 2006 to 2010, but the auditors didn’t find any problems and still issued standard opinions.

The audit quality of local CPA firms is a focus of concern in the domestic academia and practice. In China, 
the government controls both the audit market and state-owned listed companies to a large extent. The actual controller of local state-owned enterprises is the State-owned Assets Supervision and Administration Commission, so local state-owned enterprises are controlled by the local government. In the initial stage of Chinese CPA firm, they were affiliated to the government and the extension of the ministry of finance. Although the CPA firms completed decoupling reformation in 1998, the government still plays an important role in the development of local CPA firms. Both local state-owned enterprises and local CPA firms are influenced deeply by the local government; they are closer. When there is relationship between companies and accounting firms, they are more likely to receive clean audit opinions [1]. However, if the actual situation of listed companies deviates from the standard opinions, it will cause great losses to investors and disrupt order in the capital market.

This paper is a case study of two state-owned enterprises' financial fraud, whose CPA firm is the same local CPA firm. In the second part, we will introduce the details of the two companies. In the third part, we will introduce the details of the local CPA firm. In the fourth part, we will analyze the real reasons why the CPA firm still issues standard opinions for such fraud and "sick" auditors violate again. Finally, we propose some policy suggestions. This study enriches the research field of the audit quality of local CPA firms and provides new evidence. It is a huge obstacle for the healthy development of the China capital market. The regulator should play more attention on such issues.

\section{Case Introduction}

\subsection{Nanjing Zhongbei Group Co., Ltd. Financial Fraud Case}

Nanjing Zhongbei Group Co., Ltd., founded in 1979, mainly engages in public passenger transport. It listed on the Shanghai Stock Exchange in 1996.The actual controller of the company is Nanjing State-owned Assets Supervision and Administration Commission, so the company is a local state-owned enterprise.

In March 2010, the China Securities Regulatory Commission issued an administrative penalty decision to the company. They found that the company's annual reports hid huge borrowing up to 1.3 billion yuan and the related-party guarantee more than 40 million yuan in 2003 and 2004. Such a large amounts of money flowed to the Nanjing Wanzhong Co., Ltd. through various ways.

The absolutely controlling shareholder of Nanjing Wanzhong Co., Ltd. is its trade unions. Its members are mainly workers in Nanjing Zhongbei Group Co., Ltd. and Nanjing Wanzhong Co., Ltd. Besides, part of the managers of Nanjing Zhongbei Group Co., Ltd. have important role in Nanjing Wanzhong Co., Ltd. at once. It can be inferred that Nanjing Zhongbei Group Co., Ltd. enjoys much more interest and controls Nanjing Wanzhong Co., Ltd. Therefore, no matter Nanjing Zhongbei Group Co., Ltd. repays loan, pays bills or remits money to shareholder funds to Nanjing Wanzhong Co., Ltd., its biggest beneficiaries is still Nanjing zhongbei Group Co., Ltd.

Nanjing Linxin Yonghua CPA firm provided audit services for Nanjing Zhongbei Group Co., Ltd. from 1998 to 2005, a total of seven years. During the seven-year period, the auditors all issued standard opinions without reservation, that is, in 2003 and 2004, the company's financial fraud years, the auditor still issued standard opinions.

\subsection{Nanjing Textiles Import \& Export Corp., Ltd. Financial Fraud Case}

Nanjing Textiles Import \& Export Corp., Ltd., founded in 1978, mainly engages in textiles import and export. It listed on the Shanghai Stock Exchange in 2001. The actual controller of the company is also Nanjing Stateowned Assets Supervision and Administration Commission, so the company is a local state-owned enterprise.

In May 2014, the China Securities Regulatory Commission issued an administrative penalty decision to Nanjing Textiles Import \& Export Corp., Ltd. They found that the company made up profits about 344 million yuan from 2006 to 2010. Table 1 shows the profits of Nanjing Textiles Import \& Export Corp., Ltd. from 2006 to 2010. We can see that the inflated profits are 31.09 million, 42.23 million, 152 million, 60.53 million, 58.64 million respectively. Figure 1 can show the gap between the disclosure profits and the actual profits clearly. Its disclosure profits are higher than its actual profits from 2006 to 2010, especially in 2008. It means the company made up profit in these five years.

No matter the time span or the amount of inflated profits, it was more serious than Lv Da Di (now called Yuntou Ecology) and Wanfu Biotechnology Agricultural Development Co., Ltd.’s financial fraud, two serious 
Table 1. Profits of Nanjing Textiles Import \& Export Corp., Ltd. from 2006 to 2010.

\begin{tabular}{cccccc}
\hline \multirow{2}{*}{ Profit } & \multicolumn{5}{c}{ Year } \\
\cline { 2 - 6 } & 2006 & 2007 & 2008 & 2009 & 2010 \\
\hline Disclosure profits (million) & 24.40 & 27.93 & 15.80 & 15.83 & -1.05 \\
Inflated profits (million) & 31.09 & 42.23 & 152.00 & 60.53 & 58.64 \\
Actual profits (million) & -6.69 & -14.30 & -136.20 & -44.70 & -59.69 \\
Inflated profits/Disclosure profits & $127 \%$ & $151 \%$ & $962 \%$ & $382.43 \%$ & $5591 \%$ \\
\hline
\end{tabular}

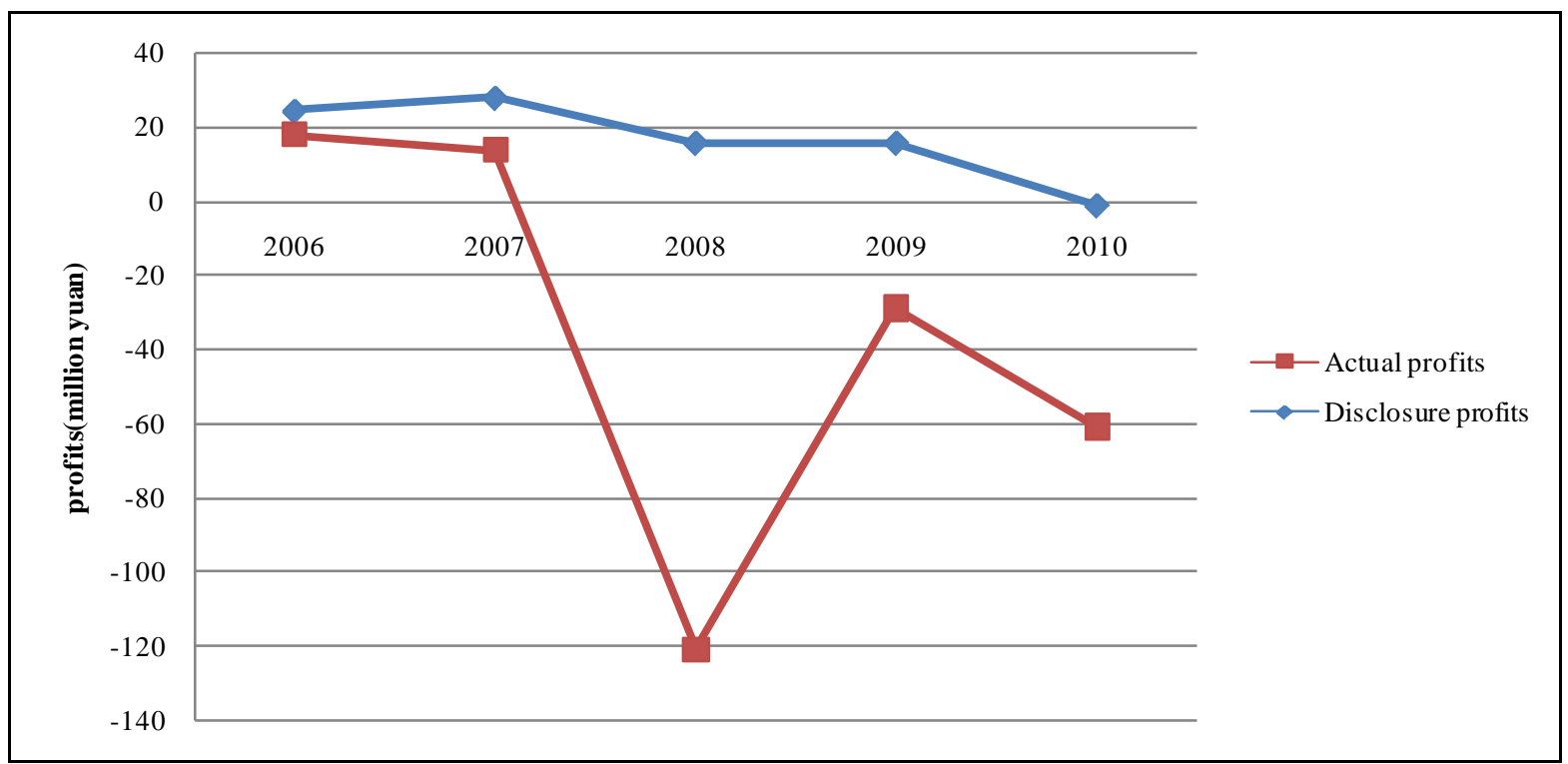

Figure 1. The actual profits and disclosure profits of Nanjing Textiles Import \& Export Corp.

financial fraud in China capital market. Lv Da Di made up profits less than 300 million yuan before it listed on the market. Wanfu Biotechnology Agricultural Development Co., Ltd. made up profits 213.68 million yuan from 2008 to first half of 2012, a total of five and a half years.

The company used various methods of financial fraud. Here were several main methods:

1) Virtually increase the revenue of contracts and forge income.

2) Carry forward less operating costs.

3) Export-tax rebate cheat: the company forged export goods documents and the amount of taxation was about 10.34 million yuan.

4) Adjust current account so as to adjust the bad debt preparation.

Nanjing Linxin Yonghua CPA firm provided audit services for Nanjing Textiles Import \& Export Corp., Ltd. from 2001 to 2011, a total of eleven years. During the eleven-year period, the auditors all issued standard opinions without reservation, that is, during the company's financial fraud year, the auditor still issued standard opinions. However, as analyzed above, the methods of financial fraud were not very complicated. They were relatively common and the fraud time lasted for five years, but the auditors didn’t find any problems.

\section{Analysis of the CPA Firm}

The financial reports of listed companies must audited by the CPA firm, so the CPA firm is an important part of the financial fraud.

The two SOEs were audited by the same CPA firm, Nanjing Lixin Yonghua CPA firm, before they were punished by China Securities Regulatory Commission.

This CPA firm is a local CPA firm. It is called Nanjing Yonghua CPA firm before, which is restructured from 
Nanjing CPA firm in December 1998, a former CPA firm affiliated to the Jiangsu Department of Finance. In February 2001, it becomes a member firm of Haohua international CPA firm. In May 2007, it joins Lixin CPA management company and changes its name to Nanjing Linxin Yonghua CPA firm.

Nanjing Lixin Yonghua CPA firm is a relative powerful local CPA firm in Jiangsu. It is the earliest accounting firm engaged in auditing and assets evaluation business in Jiangsu. Besides, it is one of the largest CPA firms and assets evaluation firms in Jiangsu. In 2011, it is one of China's top hundred CPA firms and its comprehensive evaluation of quality index ranks first in Jiangsu. All of these experiences show that Nanjing Linxin Yonghua CPA firm is a relative powerful CPA firm in Jiangsu and the auditors' ability is also professional.

We further analyze the methods of financial fraud of the two listed companies. As analyzed in the case introduction, The main method of Nanjing Zhongbei Group Co., Ltd. is related-party transaction and the major methods of Nanjing Textiles Import \& Export Corp., Ltd. are various but relatively common. These methods were not complicated. They are relatively common since they have been used by previous fraud companies many times. What's more, the fraud time of the companies is relatively long. One lasts for two years and another lasts for five years. However, the auditors didn't find any problems. If they follow the normal audit process, it is impossible that they can't find any problems.

Based on the above analysis, it can be indicated that the auditors' ability is not the main reason why they can't find any problems of the companies' financial statements.

We also found that the auditors of the two companies were almost the same. Table 2 shows the audit opinions and the auditors of Nanjing Zhongbei Group Co., Ltd. In 2003 and 2004, the auditors, Xumin Chu, Aiguo Zhang and Xiaoshuang Sun, issued standard opinions, who were punished by the China Securities Regulatory Commission. Table 3 shows the audit opinions and the auditors of Nanjing Textiles Import \& Export Corp., Ltd. The three auditors still signed for Nanjing Textiles Import \& Export Corp., Ltd. and issued standard opinions, which was untruthful opinions, misleading investors.

Why the CPA firm still issues standard opinions for such fraud and "sick" auditors violate again? If not because of their ability, what is the real reason?

\section{Cause Analysis}

\subsection{Common Interests}

The government, local SOEs and local CPA firms have a common interest.

First, in order to meet the China Securities Regulatory Commissions earnings targets for IPO, seasoned equity offerings or to avoid delisting, local SOEs, especially the loss-generating SOEs, will choose earnings management and intervention in the auditor's audit opinions. In China, if the listed companies loss continuously for three years, they will be compulsorily delisted. By this standard, Nanjing Textiles Import \& Export Corp., Ltd. should have been compulsorily delisted because its real profits are negative for five consecutive years. However, the company avoids delisting through financial fraud and now it still lists on the capital market.

Table 2. The audit opinions and the auditors of Nanjing Zhongbei Group Co., Ltd.

\begin{tabular}{ccc}
\hline Year & The audit opinion & the auditors \\
\hline 2003 & Standard opinion & Xumin Chu, Aiguo Zhang \\
2004 & Standard opinion & Xiaoshuang Sun, Aiguo Zhang \\
\hline
\end{tabular}

Table 3. The audit opinions and the auditors of Nanjing Textiles Import \& Export Corp., Ltd.

\begin{tabular}{ccc}
\hline Year & The audit opinion & The auditors \\
\hline 2006 & Standard opinion & Aiguo Zhang, Xumin Chu \\
2007 & Standard opinion & Xumin Chu, Wenliang Gu \\
2008 & Standard opinion & Xiaoshuang Sun, Xiaojie Zhu \\
2009 & Standard opinion & Aiguo Zhang, Min Wu \\
2010 & Standard opinion & Wenliang Zhu, Yongkuan Li \\
\hline
\end{tabular}


Second, the ultimate controller of state-owned enterprises is the local government. There is a link between SOEs' profits and the government's performance. The government officials have motivation to conspire with SOEs for better achievements and future promotion.

Third, the competition of CPA industry is more and more fierce. Most local CPA firms' business comes from local enterprises. The local government has a certain influence on the development of the local CPA firms, including access to potential business. In order to survive in the fierce competition and get more business, the CPA firms and auditors tend to choose collusion. For example, they will issue clean audit opinions for the listed companies even though they know the companies don't meet the standard.

The government can gain political achievement, the SOEs can obtain capital and better performance and the CPA firms can get access to business. All of them get benefit from the event, but there is no doubt that it will cause great harm to investors and disturb the normal order of the capital market.

\subsection{Lower Collusion Cost}

The government and the state-owned enterprises have the motivation to do earnings management and intervent in the audit opinions for raising more funds or for better performance, etc. Selecting the relevant CPA firms can reduce the cost of collusion [2]. Local CPA firms have a certain relationship with the local government and the government still has impact on local CPA firms, which can ensure better communication and reduce the cost of collusion.

The government controls both the audit market and state-owned listed companies to a large extent in China. In the initial stage of Chinese CPA firm, they were affiliated to the government and the extension of the ministry of finance. The CPA firm completed decoupling reformation in 1998, but the government still plays an extremely important role on the development of local CPA firm now. The government acts as a social regulator supervises the CPA industry directly, including the CPA professional qualification, professional standards, supervision and discipline. Local state-owned enterprises are controlled by local government, so local CPA firms and local state-owned enterprises are closer. There is a link between regional CPA firms and local governments. The government intervents in the auditor choice of the SOEs to a large extent, which leads to collusion among the government, regional CPA firms, and local enterprises [3]. In addition, the local state-owned listed companies and local CPA firms speak a common language and have a relatively common circle, which make them communicate with each other easier.

The state-owned listed companies, which have political connection, obviously tend to choose the local small CPA firms because of geographical preference. If the listed companies' earnings quality is the same, the probability of companies with political connection obtain non-standard audit opinions significantly lower than companies without political connection [4]. However, such standard opinions may be not consistent with the real performance of the enterprises, which will cause huge losses to investors.

\subsection{Low Violation Cost}

Although there are some regulations of punishment, the punishment is still light. In the financial fraud case of Nanjing Zhongbei Group Co., Ltd., the China Securities Regulatory Commission gave warning to Nanjing Linxin Yonghua CPA firm, confiscated the illegal income 175,000 yuan and fined 200,000 yuan. The auditors, Xumin Chu and Aiguo Zhang, were fined 80,000 yuan respectively. Xiaoshuang Sun was fined 40,000 yuan. From the perspective of the amount of punishment, such punishment is not serious compared to the amount of fraud.

The financial case of Nanjing Textiles Import \& Export Corp., Ltd. is more serious. The amount of fraud is larger and the fraud time is longer. However, the CPA firm and the auditors were not under any penalties. Only the company was warned and fined 500,000 yuan by the China Securities Regulatory Commission. Its senior executives were fined. The auditors still audit for other companies after the fraud case. They continue their work even though they violate.

The low cost of violation is also the reason why the auditors violate again and again.

\section{Policy Suggestions}

Auditing is an important part to ensure the true and reliable financial reporting. The certified public accountants 
should maintain independence and issue unbiased audit opinions. They are responsible for investors not for interest. If the CPA firms conspire with the listed companies, meaning intermediary institutions perform practically no function, it will cause huge losses to investors. It is a huge obstacle for the healthy development of the China capital market.

Finally, we put forward the following policy suggestions and measures:

1) Strengthen the external supervision and implement the audit institutions rotation system. The regulatory authority should make relevant regulations of the auditor choice and rotation so as to regulate the auditor choice of the state-owned listed companies. As the two cases studied in this paper, Nanjing Lixin Yonghua CPA firm, provide audit services for 7 years and 11 years respectively, it is easier for them to form collusion. If the companies haven't been investigated by the China Securities Regulatory Commission, Nanjing Lixin Yonghua CPA firm may continue to provide audit services for the companies. It can hinder the communication between enterprises and intermediaries and strengthen supervision through the audit institutions rotation.

2) Strengthen the punishment dynamics so as to increase the cost of violation. In the Enron's financial fraud case, the intermediaries are punished severely. JP Morgan and CitiBank are fined up to 300 million dollars. An Daxin CPA firm collapses after the event. The company's senior executives were sentenced to 100 years in prison and fined nearly 200 million dollars. However, in the Nanjing Zhongbei Group Co., Ltd. financial fraud case, Nanjing Lixin Yonghua CPA firm is only warned and fined 200,000 yuan. In another fraud case, the CPA firm has not been punished. Such punishment is obviously too light. It's not enough to deter the high frequency of illegal behavior.

3) Establish a faith file for a CPA to record his illegal behavior. In the era of big data, it is more convenient to save information and establish files. The regulatory authority can use information technology to record the illegal behavior of a CPA since he works as an auditor. If the CPA doesn't do his duty and violates the regulation, for example, issues untruthful auditor opinions, the regulatory authority should give attention to this phenomenon as well as give him warning. If the situation is serious, the auditor should be punished. This can constrain the CPA's behavior and reduce his short-sighted behavior.

\section{References}

[1] Lennox, C. (2005) Audit Quality and Executive Officers’ Affiliations with CPA Firms. Journal of Accounting and Economics, 39, 201-231. http://dx.doi.org/10.1016/j.jacceco.2003.12.002

[2] Wang, Q., Wong, T.J. and Xia, L. (2008) State Ownership, the Institutional Environment, and Auditor Choice. Journal of Accounting and Economics, 46, 112-134. http://dx.doi.org/10.1016/j.jacceco.2008.04.001

[3] Chen, J.K. and Chen, H.W. (2009) Company Characters, Audit Demand and Factors Driving Local Accounting Firm Selection. The Theory and Practise of Finance and Economic, 30, 62-66.

[4] Du, X.Q., Zhou, Z.J. and Du, Y.J. (2011) Political Connections, Regional Preference of Audit Choice and Audit Opinions. Auditing Research, 2, 78-86. 